\title{
Use of local anaesthetics in heart transplant patients
}

\author{
Effects of dental local anaesthetics in cardiac transplant recipients
}

\section{J. G. Meechan, G. Parry, D.T. Rattray and J. M. Thomason Br Dent J 2002; 192: 161-163}

\section{Objective}

To investigate the cardiovascular responses of cardiac transplant recipients to dental local anaesthetic solutions with and without epinephrine (adrenaline).

Materials and methods

A clinical study employing 30 patients (20 cardiac transplant recipients and ten healthy) awaiting gingival or minor oral surgery under local anaesthesia receiving either $4.4 \mathrm{ml}$ lidocaine (lignocaine) with 1:80,000 epinephrine or $4.4 \mathrm{ml} 3 \%$ prilocaine with $0.03 \mathrm{IU} / \mathrm{ml}$ felypressin.

\section{Results}

Cardiac transplant patients experienced a significant tachycardia 10 minutes after injection of the epinephrine-containing solution. No significant change in heart rate was detected after the injection of an epinephrine-free solution. Blood pressure was not affected. Periodontal surgery did not affect the responses to the local anaesthetics in the transplant recipients.

\section{Conclusions}

The cardiovascular response to dental local anaesthesia in cardiac transplant recipients is governed by the solution injected.

\section{IN BRIEF}

- Transplanted hearts are supersensitive to the effects of circulating catecholamines. This paper examines the haemodynamic effects of dental local anaesthetics containing 1:80,000 epinephrine (adrenaline) in patients with cardiac transplants.

- The epinephrine in dental local anaesthetics did not affect blood pressure in cardiac transplant recipients.

- Epinephrine contained in dental local anaesthetics significantly increased heart rate in cardiac transplant recipients before periodontal surgery.

- Surgery did not mask the haemodynamic changes produced by the local anaesthetic in cardiac transplant recipients.

- Epinephrine-free solutions may be preferred for dental local anaesthesia in cardiac transplant recipients.

\section{COMMENT}

Dr Meechan and his colleagues have examined the effects of local anaesthetic administration for dental treatment in a small, but important, group of patients.

Cardiac transplantation is now 'main-stream' treatment, and there is a significant number of patients in the community who have benefited from this procedure. These patients require dental care, and might present to a general dental practitioner although I suspect that the majority will seek hospital treatment.

Patients with recently transplanted, denervated hearts respond to injections of dental local anaesthetics containing epinephrine with an increased heart rate. However, no increases in blood pressure were recorded.

The authors are very cautious and recommend avoiding preparations containing epinephrine for this small group of patients. It is clear from the result that a significant increase in heart rate can occur at ten minutes post-injection, but whether this presents a significant risk is uncertain.

This report refers to the lack of haemodynamic response by patients without cardiovascular disease to the administration of lidocaine with epinephrine. Whilst agreeing that it is not unreasonable to use a local anaesthetic preparation without epinephrine in patients who have recently been the recipient of a transplanted heart, this should not reinforce prejudices about the use of local anaesthetics containing epinephrine for most patients.

Professor J. P. Rood

Consultant, Oral and Maxilofacial Surgery

Guy's King's and St Thomas' Dental Institute. 